\title{
A RELATION BETWEEN TWO CLASSES OF INDEFINITE WEIGHTS IN SINGULAR ONE-DIMENSIONAL $p$-LAPLACIAN PROBLEMS
}

\author{
JISOO BYUN AND INBO SIM
}

Abstract. We introduce several types of classes of an indefinite weight $h$ in singular onedimensional $p$-Laplacian problems

$$
\varphi_{p}\left(u^{\prime}(t)\right)^{\prime}+h(t) f(u(t))=0,
$$

where $\varphi_{p}(x)=|x|^{p-2} x, p>1$ and $h \in C((0,1),[0, \infty))$ may be singular at 0 and/or 1 and $f \in C(\mathbb{R}, \mathbb{R})$. We show a relation among them according to $p$ employing Minkowski inequality and integral transformations.

Mathematics subject classification (2000): 34A12, 34B15. inequality.

Keywords and phrases: Singular one-dimensional $p$-Laplacian problem, indefinite weight, Minkowski

\section{REFERENCES}

[1] R. P. Agarwal And H. LÜ AND D. O'Regan, Eigenvalues and the one-dimensional p-Laplacian, J. Math. Anal. Appl. 266 (2002) 383-400.

[2] H. ASAKAWA, Nonresonant singular two-point boundary value problems, Nonlinear Anal. 47 (2001) 4849-4860.

[3] M. GarCía-Huidobro AND R. MANÁSEVICH AND J. R. WARD, A homotopy along $p$ for systems with a vector p-Laplace operator, Advances in Differential Equations 8 (2003) 337-356.

[4] B. IM AND E. LEE AND Y. LEE, A global bifurcation phenomena for second order singular boundary value problems, J. Math. Anal. Appl. 308 (2005) 61-78.

[5] L. Kong AND J. WANG, Multiple positive solutions for the one-dimensional $p$-Laplacian, Nonlinear Anal. 42 (2000), 1327-1333.

[6] Y. H. LEE AND I. SIM, Global bifurcation phenomena for singular one-dimensional p-Laplacian, J. of Differential Equations 229 (2006) 229-256.

[7] Y. H. LEE AND I. SIM, Existence results of sign-changing solutions for singular one-dimensional p-Laplacian problems, Submitted.

[8] H. LÜ AND D. O'REGAN, A general existence theorem for the singular equation $\left(\varphi_{p}\left(y^{\prime}\right)\right)^{\prime}+f(t, y)=0$, Math. Inequalities and Applications 5 (2002) 69-78.

[9] R. ManÁSEvich AND J. MaWhin, Periodic solutions of nonlinear systems with p-Laplacian-like operators, J. of Differential Equations 145 (1998) 367-393.

[10] J. SÁNCHEZ, Multiple positive solutions of singular eigenvalue type problems involving the onedimensional p-Laplacian, J. Math. Anal. Appl. 292 (2004) 401-414.

[11] J. WANG, The existence of positive solutions for the one-dimensional $p$-Laplacian, Proc. Amer. Math. Soc. 125 (1997), 2275-2283.

[12] X. YANG, Sturm type problems for singular p-Laplacian boundary value problems, Applied Math. and Com. 136 (2003) 181-193.

[13] M. ZHANG, Nonuniform nonresonance of semilinear differential equations, J. of Differential Equations 166 (2000) 33-50. 